\title{
ANÁLISE DA QUALIDADE VISUAL DA PAISAGEM DE PRAIAS ARENOSAS NA ORLA DE ITAJAÍ-SC
}

\author{
BELINO, J.A.T ${ }^{1 *}$; BELTRÃO, M.C ${ }^{1}$. \& MARENZI, R. C. ${ }^{1}$ \\ 1. Universidade do Vale do Itajaí - UNIVALI \\ ${ }^{*}$ Corresponding author: jose_belino@hotmail.com
}

\begin{abstract}
Belino, J.A.T ${ }^{1}$; Beltrão, M.C ${ }^{1}$. \& Marenzi, R. C. ${ }^{1}$ (2018). Análise da qualidade visual da paisagem de praias arenosas na orla de Itajaí-SC. Braz. J. Aquat. Sci. Technol. 21(2). eISSN 1983-9057. DOI: 12459/bjast.v21n2. The Visual Quality of Landscapes of an area is an important element to be considered in the management of coastal zones. This work aims to analyze the Visual Quality of Landscapes of the beaches Atalaia, Brava (North and South) and Cabeçudas, in order to understand and relate the landscape preferences of beaches goers. For the analysis of the Visual Quality of the Landscape, the direct method was used, based on the classification of Ignacio et al. (1984), through 24 photographs of the sites under study, used during the assessment by 76 interviewees. The samples were taken during the Carnaval and Tiradentes holidays in 2017. A general average of 3.59 (High Quality Landscape) was verified for the Visual Quality of Landscape, being 4.54 (Very High Quality Landscape) the highest, and 2.97 (Medium Quality Landscape) the lowest grade. In this study, the use of Landscape Visual Quality through the direct method proved to be effective, showing a trend towards greater appreciation of the beaches that exhibit more natural elements when compared to the more urbanized beaches.

Key Words: Landscape Quality; Environmental Perception; Itajai's Shoreline.
\end{abstract}

\section{INTRODUÇÃO}

As regiões costeiras destacam-se por sua paisagem, no litoral catarinense são compostas por um conjunto de belas praias, costões e formações vegetais, atraindo o turismo e a ocupação urbana. De acordo com Laurie (1976) paisagem é definida como um espaço que, quando visto ou descrito em termos de suas características (fisiográficas e ambientais), relacionadas com os impactos antropogênicos, é de grande importância nos estudos de planejamento urbano e regional. De acordo com Siles (2003), a paisagem pode ser transformada através do processo de urbanização, e os fatores relacionados à sustentabilidade devem ser levados em consideração durante o planejamento.

Landovsky et al. (2006) afirmam que o estudo da paisagem é utilizado no planejamento regional em diversos países sendo, inclusive, determinante na implantação ou não de um projeto ou obra de engenharia. Por tanto, a valoração da paisagem pode ser considerada um recurso que permite avaliar a qualidade visual de uma região, quando aliada às técnicas de sensoriamento remoto sendo, ainda, viável econômica e tecnicamente, nas questões de planejamento urbano, regional e de uso do solo.

A paisagem, assim como sua qualidade visual, podem sofrer modificações em decorrência da alta concentração de turistas, e tais alterações, muitas vezes colocam em risco o ambiente e seu atrativo turístico (Ignarra, 1999; Piatto \& Polette, 2012). Sendo assim, Delúcio \& Múgica (1994) reconhecem a paisagem como um importante recurso a ser considerado, e que o estudo da Qualidade Visual da Paisagem (QVP) é um dos principais objetivos na demanda recreacional. Os mesmos ainda destacam que paisagens e ambi- entes esteticamente agradáveis podem influenciar o bem-estar humano. Com isto, estudos relacionados a QVP podem auxiliar no planejamento e zoneamento de uso do solo, além de contribuir na implantação e manejo de Unidades de Conservação (Marenzi, 2000).

A realização de estudos de qualidade ambiental urbana através da percepção vem sendo considerada fundamental, uma vez que é necessário conhecer a qualidade e a intensidade da experiência do homem com o ambiente (Tuan, 1983). Entendendo assim, como os indivíduos compreendem o ambiente e suas causas de satisfação e insatisfação (Faggionato, 2007). De acordo com Silva et al. (2016), a partir de estudos de percepção seria possível observar uma melhoria visível na qualidade ambiental urbana.

A avaliação da QVP é baseada na análise da percepção de cada indivíduo, e pode ser obtida através dos métodos: indireto, em que a valoração é realizada através da desagregação da paisagem e da análise dos elementos da paisagem, e segundo critérios de pontuação e classificação estabelecidos por especialistas; direto, onde o valorador classifica a paisagem por meio de observação no local ou por um substituto; e misto, quando a valoração é feita primeiro de forma direta, e posteriormente é realizado o estudo da participação de cada componente ou elemento no valor total da paisagem através de análises estatísticas, (Pires, 1993).

$O$ método direto destaca-se por ser mais simples (e mesmo assim eficaz) na obtenção dos dados quando comparado com os demais. De acordo com Ignacio et al. (1984), este método é realizado através da observação da paisagem como um todo, seja com a visualização no local, ou pelo uso de fotografias, slides, vídeos e gravuras, dando origem a diferentes níveis de subjetividade durante 
o processo. No estudo da QVP o avaliador poderá ser o público em geral, grupos representativos da sociedade ou, ainda, profissionais paisagistas.

Pesquisas utilizando a percepção ambiental dos usuários de praias vem sendo desenvolvidas para avaliar a qualidade de ambientes costeiros (Micallef \& Williams 2004). Sousa (2011) cita a opinião de usuários de praias, através da percepção sobre o ambiente costeiro utilizado para recreação, como uma ferramenta utilizada em planos e programas de gestão costeira.

Por tanto, considerando a importância da qualidade visual da paisagem tanto no aspecto ecológico, quanto econômico, este trabalho tem como objetivo analisar a Qualidade Visual da Paisagem (QVP) nas praias da Atalaia, Brava e Cabeçudas, sendo estas, áreas que apresentam grande potencial turístico no litoral norte do estado de Santa Catarina. Pretendendo compreender a percepção dos frequentadores das praias através das preferências paisagísticas.

\section{MATERIAIS E MÉTODOS}

Área de Estudo

Foram estudadas as praias da Atalaia, Cabeçudas e Brava (Norte e Sul), localizadas no litoral norte de Santa Catarina-BR, as quais apresentam diferentes níveis de urbanização e compõem o Estudo de Delimitação de duas Unidades de Conservação na Orla de Itajaí (Figura 1).

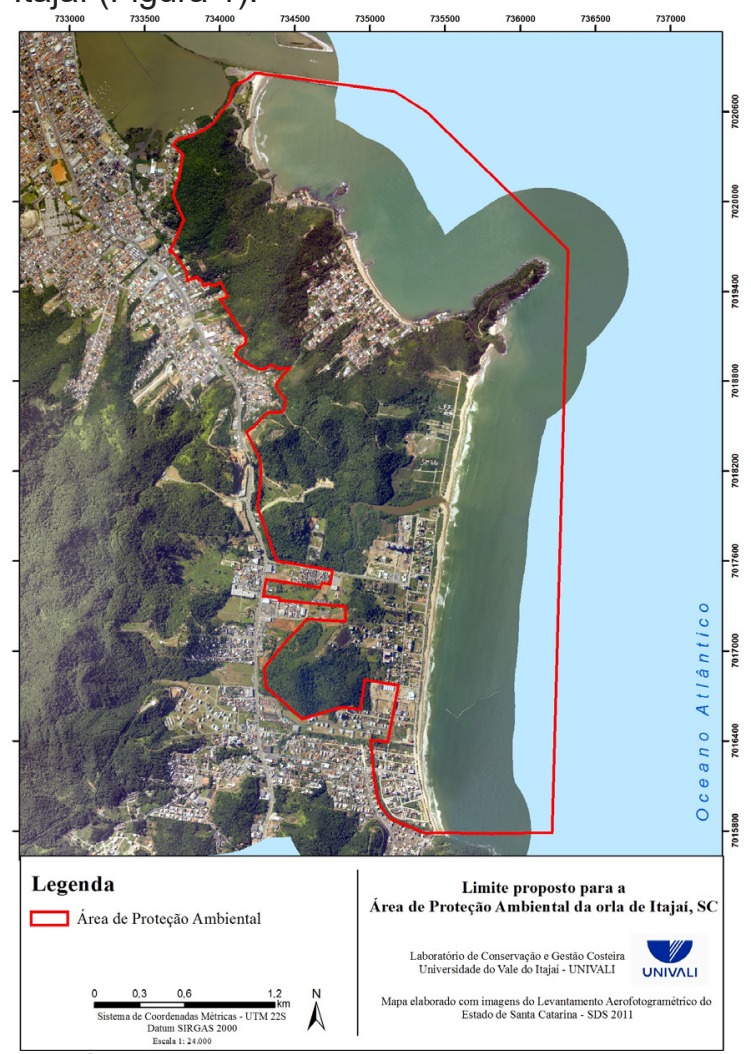

Figura 1- Área de estudo onde será implantada a APA em Itajaí,SC. Fonte: Laboratório de Conservação, Gestão e Governança Costeira.
A praia da Atalaia com extensão de 630 metros e 66 metros de faixa de areia está localizada na foz do rio Itajaí-Açú, sendo esta, uma das praias mais frequentadas para turismo de sol e praia da cidade (Menezes \& Scolaro, 2017). Na faixa de areia da praia não há a presença de residências, apenas bares e quiosques utilizados durante o verão. Enquanto a praia de Cabeçudas possui aproximadamente 900 metros de extensão, e localiza-se cerca de três quilômetros ao sul da foz do rio Itajaí-Açu (Schmitt \& Proença, 2010). Esta apresenta urbanização bem consolidada e tradicional, com ruas pavimentadas e arborizadas, suas construções são predominantemente residenciais de médio porte.

Já a praia Brava com aproximadamente 12 quilômetros de comprimento, dividida pela Lagoa do Cassino localiza-se entre os promontórios da ponta do Morcego, ao norte, e da ponta da Preguiça, ao sul. Sendo formada por um complexo de dunas, restingas e mata atlântica em relativo estado de conservação, o que potencializa o interesse turístico na região (Guedes \& De Araújo, 2010). Esta praia apresenta uma história de ocupação mais recente, quando comparada a outros bairros, tendo seu desenvolvimento ocorrido principalmente a partir do final do século passado, e ainda estando em processo crescente de urbanização (Univali, 2016)

\section{Levantamento da Qualidade Visual da Paisagem}

A Qualidade Visual da Paisagem (QVP) foi obtida através do método direto, onde, a valoração é realizada com base na contemplação de toda a paisagem (Marenzi, 1996). Este método pode ser utilizado a partir da visualização no local o com uso de substitutos, neste estudo foram utilizadas fotografias para representar as áreas estudadas.

Com o uso de uma câmera fotográfica (Canon t3i) foram capturadas fotografias para as orientações norte, sul, leste e oeste em três pontos equidistantes em cada uma das praias. Para reduzir o número de fotos que os usuários precisariam valorar, tornando a pesquisa mais atraente, algumas fotos foram descartadas. Para o estudo foram escolhidas as fotos que mais representassem as praias. Por fim, um total 24 fotos com tamanho $23,5 \times 12 \mathrm{~cm}$ foram usadas para a valoração.

Os questionários foram aplicados em fevereiro e abril de 2017, e após os avaliadores assinarem um Termo de Consentimento Livre e Esclarecido, os mesmos valoraram cada uma das 24 fotografias em classes de 1-5 pontos (Tabela 1), com base em Marenzi (1996). Durante a pesquisa, ressaltou-se aos participantes que a fotografia deveria ser avaliada apenas quanto a qualidade da paisagem, não em relação a técnica fotográfica. 
Tabela 1 - Classes de Qualidade Visual da Paisagem

\begin{tabular}{cc}
\hline Classe & Qualidade Visual \\
\hline 1 & Paisagem de Qualidade muito baixa (péssima) \\
2 & Paisagem de Qualidade Baixa (ruim) \\
3 & Paisagem de Qualidade Média (regular) \\
4 & Paisagem de Qualidade Alta (boa) \\
5 & Paisagem de Qualidade Muito Alta (ótima) \\
\hline
\end{tabular}

\section{Análise da Qualidade Visual da Paisagem}

Após a aplicação dos questionários, a análise da QVP foi calculada a partir da média das notas das fotografias de cada praia, a fim de classificar quanto a sua Qualidade Visual da Paisagem. Posteriormente, foi analisado se o número de entrevistados era suficiente para valoração das fotografias com base na variância de cada uma. Para isso utilizou-se a fórmula segundo Steel \& Torrie (1960, apud Marenzi, 1996):

$$
n=\frac{\delta^{2} \cdot t^{2}}{\&^{2}}
$$

onde: $n=$ número ideal de entrevistados por foto

$\delta^{2}=$ variância de cada foto

$\mathrm{t}=1,993$ (valor tabelado obtido para $\mathrm{n}-1=75 \mathrm{e}$ $95 \%$ de confiança)

\&=erro admissível ( $10 \%$ da média)

Foi visto que 44 era o número médio de valoradores necessários para avaliar a Qualidade Visual da Paisagem de cada uma das fotografias. E que em nenhuma das 24 fotografias utilizadas nesse estudo houve a necessidade de mais de 73 valoradores.

\section{RESULTADOS E DISCUSSÕES}

\section{Perfil Dos Entrevistados}

Foram entrevistados 76 usuários de praias, sendo a maior parte deles moradores de Itajaí (42\%), seguido por moradores de Balneário Camboriú (19\%), Blumenau (7\%), Brusque (7\%), São Paulo (5\%) e Itapema (5\%).Os demais entrevistados residiam em outras cidades de Santa Catarina (Gaspar e Camboriú) ou em outros estados do país (Paraná, Rio Grande do Sul, Mato Grosso do Sul, Maranhão e Minas Gerais). Já era esperada uma maior contribuição de moradores de Itajaí nas entrevistas, uma vez que as praias estudadas estão inseridas dentro do município, assim como uma grande contribuição de moradores residentes em Balneário Camboriú, devido à proximidade com a área de estudo. No entanto, o número de entrevistados residentes no município de São Paulo-SP revela um interesse pelas praias da região.
Quanto a contribuição por gênero dos avaliadores, $57 \%$ dos entrevistados eram do gênero masculino e $43 \%$ do gênero feminino, com a faixa etária variando entre 18 e 63 anos, resultando em um valor médio de 37 anos de idade (Figura 2). Foi possível observar que a amostra era adequadamente distribuída em termos de gênero e faixa etária. A maior parte dos entrevistados (54\%) neste trabalho foram pessoas mais jovens, com idades entre 18 e 35 anos. Venson (2009) verificou que nas praias Brava Norte e Brava Sul $75 \%$ dos seus usuários possuíam idade entre 18 e 34 anos.

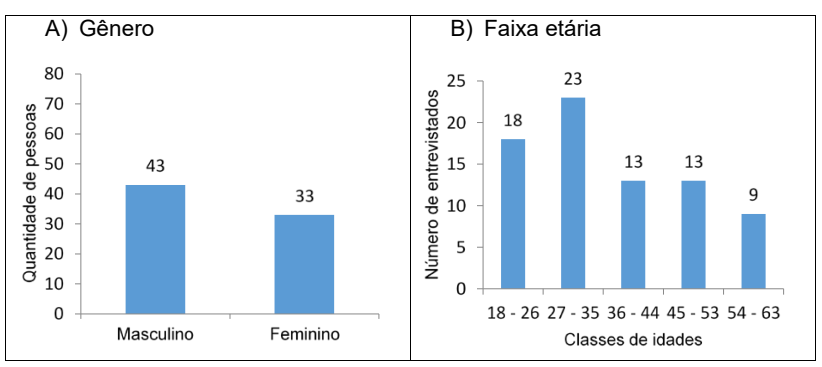

Figura 2. Gênero e faixa etária dos entrevistados, Itajaí-SC.

\section{Qualidade Visual da Paisagem}

Neste estudo, foram analisadas no total 24 fotografias, sendo apenas uma fotografia (4\%) valorada como Paisagem de Qualidade Muito Alta - Ótima, 11 $(46 \%)$ como Paisagem de Qualidade Alta - Boa e 12 fotografias $(50 \%)$ como Paisagem de Qualidade Média - Regular. Nenhuma das fotografias obteve como médias as notas 1 e 2 , sendo a maior parte delas valoradas nas classes 3 e 4 . Demonstrando que segundo os avaliadores, grande parte da área de estudo encontra-se com Qualidade Visual da Paisagem de média a ótima.

As fotografias com maior valoração foram paisagens da praia da Atalaia com vista do mar e ponta da morraria (Figura $3 \mathrm{~A}$ ), da Brava (Norte) no Canto do Morcego (Figura $3 \mathrm{~B}$ ), e nas praias Brava (Sul) e Cabeçudas, ambas com a vista do mar (Figura $3 \mathrm{C}$ e D).

Dentre as quatro fotografias de maior apreciação, uma é classificada com qualidade Muito Alta - Ótima, e as demais na classe de Qualidade Alta Boa. Contudo, todas apresentaram elementos naturais em sua totalidade (mar, areia da praia e/ou costão rochoso). Segundo Bildhauer \& Pires (2015) a água do mar, a paisagem como um todo, a natureza, os morros e as pedras são considerados como aspectos positivos na paisagem. Estes elementos também foram observados por Marenzi (1996) e Félix et al. (2016), que constataram que as fotografias avaliadas com maior pontuação apresentavam água e relevo acentuado na paisagem. Gonzaga et al. (2004) estudando a qualidade visual da paisagem da Trilha Ecológica 
do Parque Municipal do Passaúna, afirmam que a presença em abundância do elemento água pode ter contribuído para uma sensibilização favorável dos avaliadores e influenciado na determinação de uma classificação média "boa".
Scandiuzii (2012) afirma que uma mesma paisagem pode ser interpretada de diferentes formas, dependendo do olhar de quem a observa, entretanto, as mesmas exibem um conjunto de características que possibilita indicar sua qualidade ambiental.
A) Atalaia (nota 4,54)

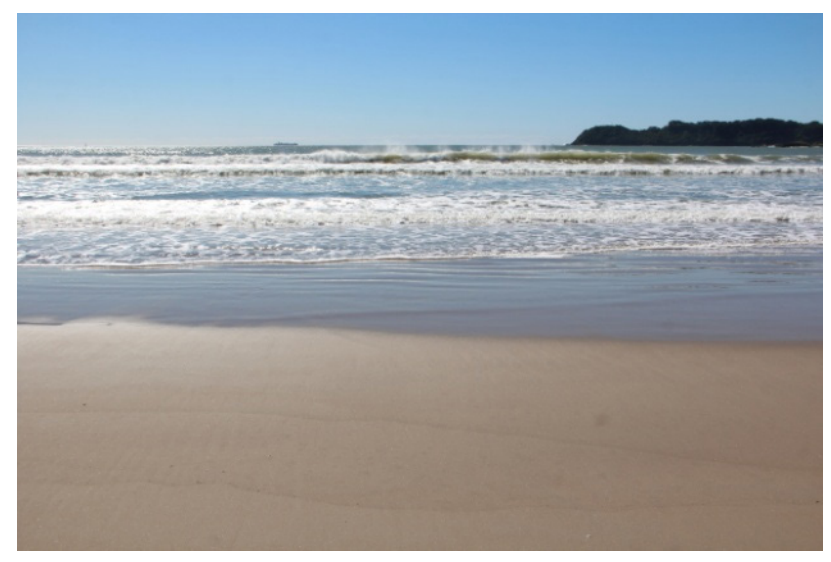

C) Brava Sul (nota 4,33)

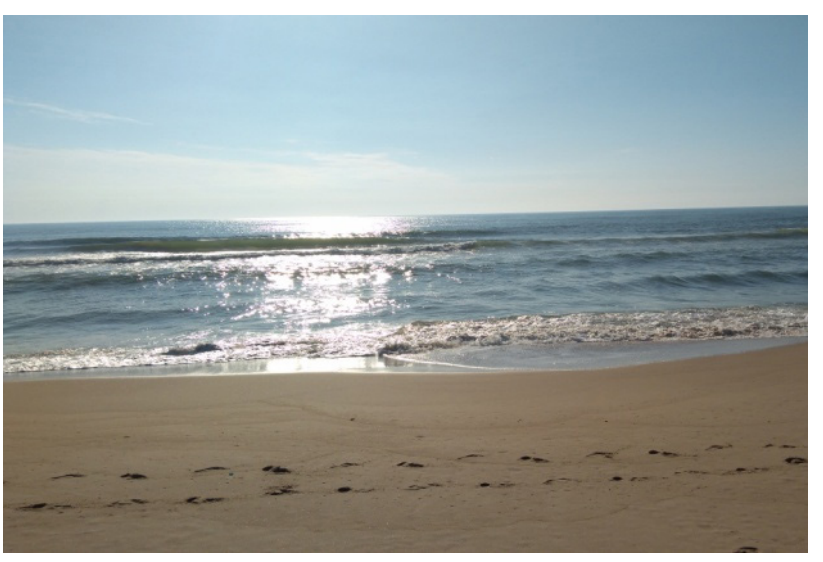

B) Brava Norte (nota 4,41)
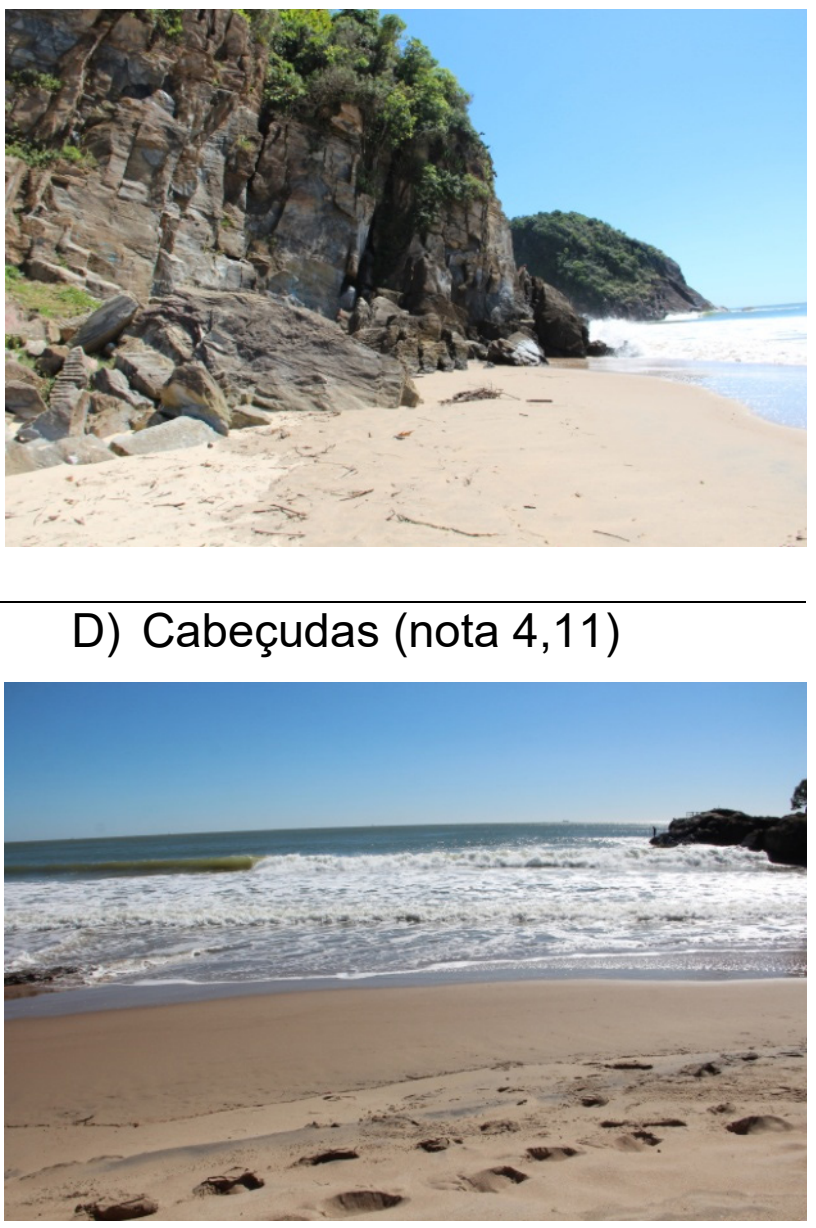

Figura 3. Imagens de maior valoração na área de estudo, por ordem de importância. A- Atalaia, B - Brava (norte), C - Brava (Sul) e D - Cabeçudas

Neste caso, os elementos naturais presentes nas fotografias podem ter sido utilizados pelos avaliadores como características para avaliação da qualidade visual.

Todas as quatro fotografias que apresentaram menor valoração foram classificadas com Qualidade Média - Regular, sendo duas de Cabeçudas (Figura 4 B e D), uma da Atalaia (Figura 4 C), e uma da Brava Sul (Figura 4 A). Nestas fotografias é possível observar a urbanização como elemento comum, Moore \& Foley (2005) e O'Neill et al. (1996) admitem que as formas antropogênicas são consideradas como efeito negativo na paisagem. Corroborando, Pires (2005) cita a forte incidência humana como detrator visual da qualidade paisagística. Em um trabalho realizado por Bildhauer \& Pires (2015) o desmatamento no continente, água suja (sujeira trazida pela maré e algas, por exemplo) e o pouco espaço de faixa de areia foram pontos negativos citados pelos entrevistados.

Landovsky et al. (2006) concluíram em seu estudo que os aspectos negativos visualizados por seus entrevistados estão relacionados à intervenção antrópica, sobretudo, nas áreas de agricultura de vasta extensão territorial e de reflorestamentos. 
A) Brava Sul (nota 3,07)

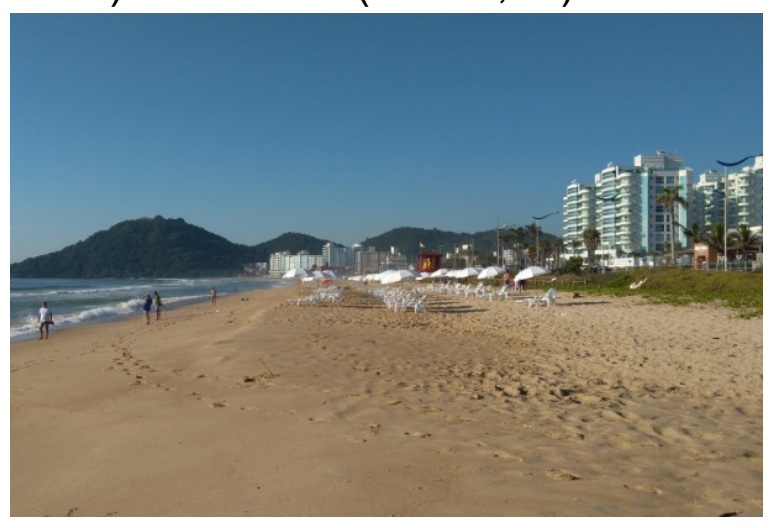

C) Atalaia (nota 3,05)

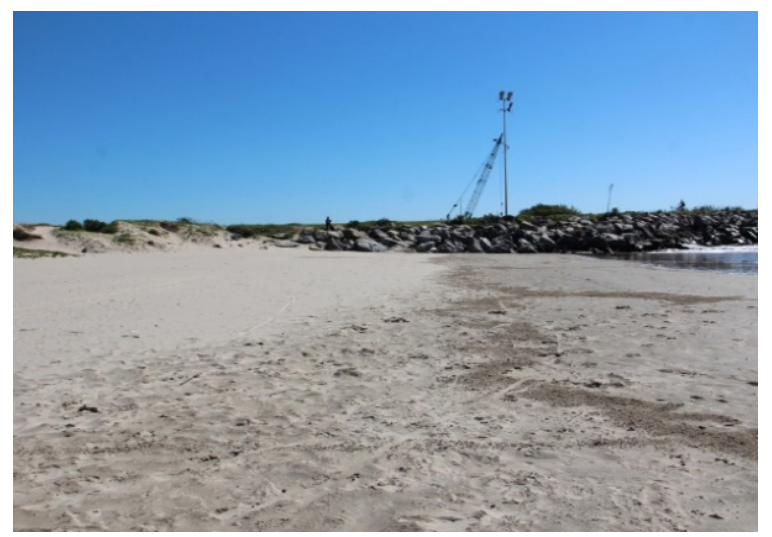

B) Cabeçudas (nota 3,05)

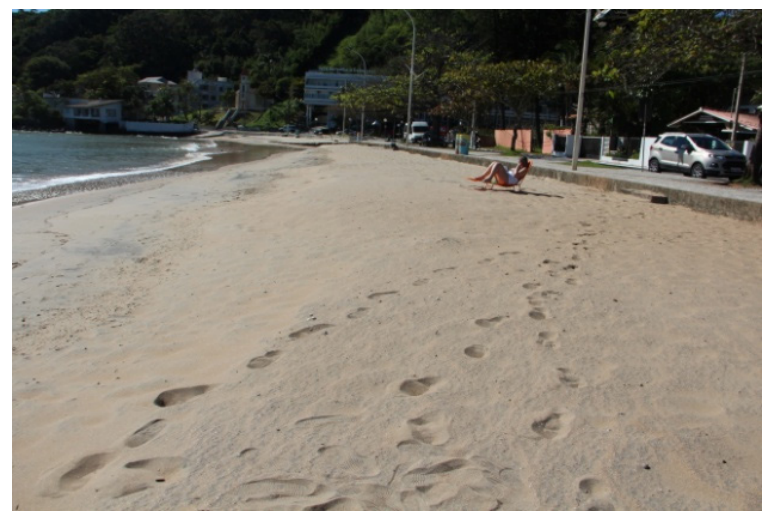

D) Cabeçudas (nota 2,97)

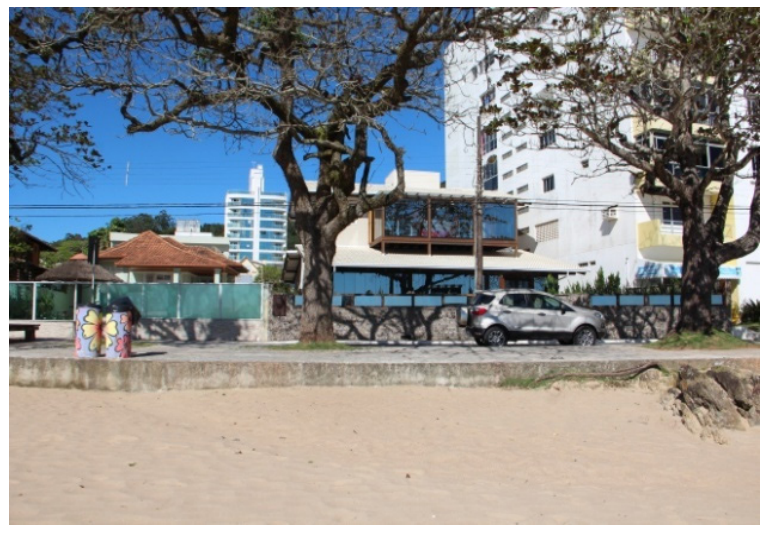

Figura 4. Imagens de menor valoração na área de estudo, em ordem de menor preferência. A- Brava (Sul), B - Cabeçudas, C - Atalaia e D - Cabeçudas

Neste estudo a praia da Atalaia apresentou Qualidade Visual da Paisagem média de 3,57 (Paisagem de Qualidade - Alta), Cabeçudas de 3,45 (Paisagem de Qualidade Média), e Brava Norte e Sul de 3,69 e 3,45 (Paisagem de Qualidade - Média) respectivamente. Trabalhos realizados em ecossistemas costeiros, tais como os de Marenzi (1996) e Félix et al. (2016), também mostram resultados similares.

A única foto valorada na classe Paisagem de Qualidade Muito Alta - Ótima neste estudo foi na praia da Atalaia, com isto, observa-se que a presença dos elementos naturais está entre os fatores que mais contribuíram para maior valoração desta praia. No entanto, ao analisar a vista do continente, foi observado que apenas exibir elementos naturais não determinou tal classificação, pois fica clara a necessidade de estruturas, mesmo que artificiais, que possibilitem a realização das atividades turísticas. Félix et al. (2016), conclui que, uma vez urbanizada, a presença de serviços e infraestrutura aumenta a valoração da praia. A segunda fotografia que apresentou a maior nota média de valoração da QVP foi do costão rochoso no Canto do Morcego, localizado na porção norte da praia Brava.
López-Martínez (2017) e Pires (1993) ressaltam as encostas como elemento positivo na qualidade da paisagem. No entanto, Siebert (2008) classifica a Praia Brava como a área mais vulnerável de Itajaí à degradação ambiental, estando sujeita a um processo iminente de transformação sócio espacial.

Dentre as praias estudas, Cabeçudas foi a que apresentou menor média de QVP, segundo Fagundes (2014), esta praia apresenta sua ocupação urbana iniciada na década de 1920, e hoje ostenta um bairro bem consolidado, com a presença de edificações, bares, quiosques e restaurantes. Embora Costa (2011) considere que as estruturas antrópicas, como a construção civil, fazem parte da paisagem, Bastarz \& Biondi (2011) acrescentam que as características atraentes aos turistas, constituem um "fator decisório de viagem", gerando investimentos e benefícios advindos do turismo. Portanto, a adoção adequada de infraestrutura deve incluir um padrão arquitetônico estético. Uma vez que um ambiente esteticamente agradável pode influenciar no bem-estar humano (Delúcio \& Múgica, 1994). 


\section{CONCLUSÕES}

A utilização do método direto no levantamento da Qualidade Visual da Paisagem das praias se mostrou eficaz, possibilitando analisar a subjetividade dos entrevistados em relação às preferências paisagísticas. Visto que, deve-se considerar a percepção dos usuários das praias para uma gestão mais eficaz. Contudo, o uso do método misto para a classificação da QVP poderia tornar a análise mais objetiva, por permitir atribuição de peso às variáveis da paisagem.

Este trabalho apontou uma análise de QVP coerente, no qual as praias que exibem mais elementos naturais foram melhor valoradas que as urbanizadas. A praia de Cabeçudas apresenta uma urbanização bem consolidada e com maior disponibilidade de estruturas de bens e serviços, seguida da Brava (Sul). Nestas praias é importante a padronização de tais estruturas, além de buscar utilização de materiais harmônicos com as necessidades de uma Unidade de Conservação. Diferente, as praias da Atalaia e Brava (Norte) apresentam menor disponibilidade de bens e serviços, e poucas residências em seu entorno, portanto, nestas áreas deve-se buscar alternativas de modelos construtivos, principalmente evitando a verticalização e adensamento populacional.

\section{REFERÊNCIAS}

Bastarz, C. \& Biondi, D. 2011. Aplicação do Método $Q$ para a valoração da paisagem de Morretes, Paraná, Brasil, como subsídio ao planejamento do turismo. Revista Turismo em Análise. 22.3: 651-680.

Bildhauer, M. \& Pires, P. S. 2015. Nova configuração metodológica para a determinação da Capacidade de Carga turístico-recreativa do destino ilha de Porto Belo, Porto Belo-SC, sob a perspectiva da sustentabilidade ambiental. 2015. Iniciação Científica. (Graduando em Turismo e Hotelaria) Universidade do Vale do Itajaí, Conselho Nacional de Desenvolvimento Científico e Tecnológico.

Costa, P. F. B. 2011. Análise visual da paisagem. Caso de estudo - Concelho de Almada. Dissertação de mestrado. Instituto Superior de Agronomia. Lisboa. 169p.

Delúcio, J. V. \& Múgica, M. 1994. Landscape preferences and behaviour of visitors to spanish national parks. Landscape and Urban Planning, Amsterdam, $n^{\circ} 29$, p. $145-160$.

Faggionato, S. 2007. Percepção ambiental. Disponível em:<http://educar.sc. usp.br/biologia /textos/m_a txt4.html>. Acesso em: 25 nov. 2016.

Gonzaga, C. A., Wandembruck, A., Seger, C. D., \& Biondi, D. 2004. Análise paisagística da trilha recreativa do Parque Municipal do Passaúna, Curitiba, Paraná. Cadernos da Biodiversidade, 4(2), 68-75.

Guedes, S. Z. \& De Araújo, S. A. 2010. Análise da qualidade de vida do bairro Praia Brava-Itajaí (SC), a partir de indicadores sociais. Geografia (Londrina), v. 13, n. 2, p. 65-90.

Ignacio, C. F. et al. Guia para elaboración de estúdios del médio físico: contenido y metodologia. 2.ed. Madrid: CEOTMA 1984. 572 p. (Série Manuales; 3)

Ignarra, L. R. 1999. Fundamentos do Turismo. $1^{\text {a }}$ Edição, São Paulo: Pioneira. 205p.

Landovsky, G. S.; Batista, D. B. \& Araki, H. 2006. Análise da Qualidade Visual da Paisagem da região de Tibagi, PR, aplicando o sensoriamento remoto. Revista Brasileira de Engenharia Agrícola e Ambiental, 10.1: 188-195.

Laurie, M. 1976. An introducion to landscape architeture. New York: Elsevier. 213p.

López-Martínez, F. 2017. Visual landscape preferences in Mediterranean areas and their socio-demographic influences. Ecological Engineering, 104: 205-215.

Marenzi, R. C. 2000. A análise da Qualidade Visual da Paisagem como instrumento da ecologia da paisagem. Anais do I Fórum de Debates em Ecologia da Paisagem e Planejamento Ambiental. UNESP - Rio Claro (SP).

Marenzi, R. C. 1996. Estudo da valoração da paisagem e preferências paisagísticas no município da Penha-SC. 119p. Dissertação (Mestrado em Ciências Florestais) - Setor de Ciências Agrárias, Universidade Federal do Paraná, Curitiba.

Menezes, J. T. \& Scolaro, T. 2017. Ambiente Praial. In: Diehl, F. (eds). Atlas Ambiental da Foz do Rio Itajaí-Açu. 1 ed. Ed Chilicon. Itajaí. 58-67p.

Micallef, A. \& Williams A. T. 2004. Application of a novel approach to beach classification in the Maltese Islands. Ocean \& Coastal Management. 47(6): 225- 242.

Moore, B. D. \& Foley, W. J. 2005. Tree use by koalas in a chemically complex landscape. Nature. 435 (7041): 488-490.

O'neill, R. V.; Hunsaker, C. T.; Timmins, S. P.; Jackson, B. L.; Jones, K. B.; Riitters, K. H. \& Wickham, J. D. 1996. Scale problems in reporting landscape pattern at the regional scale. Landscape ecology. 11(3): 169-180.

Piatto, L. \& Polette, M. 2012. Análise do Processo de Artificialização do Município de Balneário Camboriú, SC, Brasil. Revista da Gestão Costeira Integrada 12(1):79-90.

Pires, P. S. 2005. A análise de indicadores da qualidade visual como etapa da caracterização de paisagens turísticas: uma aplicação no distrito-sede de 
Porto Belo-SC. Turismo: visão e ação. Balneário Camboriú, n. 3, v. 7.

Pires, P. S. 1993. Avaliação da Qualidade Visual da Paisagem na região carbonífera de Criciúma-SC. Curitiba. Dissertação (Mestrado em Engenharia Florestal), Pós-Graduação em Engenharia Florestal do Setor de Ciências Agrárias, UFP.

Scandiuzii, L. 2012. Valoração da Paisagem: análise das praias da Jureia, Barra do Una e Preta. Trabalho de conclusão de curso apresente ao Instituo Federal de Educação, Ciência e Tecnologia. São Paulo.

Schmitt, F. \& Proença, L. A. 2010. Ocorrência de dinoflagelados do gênero Dinophysis (Enrenberg, 1839) na Enseada de Cabeçudas (verão e outono de 1999). Brazilian Journal of Aquatic Science and Technology, v. 4, n. 1, p. 49-59.

Siebert, C. A. F. 2008. Território em disputa: santuário ou filão turístico imobiliário? A Praia Brava de ItajaíSC. IV Encontro Nacional da ANPPAS.

Siles, M. F. R. 2003. Modelagem espacial para atividades de visitação pública em áreas naturais. Universidade de São Paulo.

Silva, D. D. M.; Santos, N. R. Z.; Vogel, H. \& Weber, M. A. 2016. The population of São Gabriel city, RS and satisfaction level in relation to urban environmental quality. Ciencia e Natura. 38(2): 847-861.

Sousa, R. C. 2011. Capacidade de Carga recreacional, percepção dos usuários e qualidade da água em três praias turísticas da Costa amazônica. Master'sThesis. Universidade Federal do Pará.

Fagundes, T. 2014. Enseada de Cabeçudas: a formação sócio-espacial do balneário. Dissertação (Mestrado em Urbanismo, História e Arquitetura da Cidade) - Universidade Federal de Santa Catarina, Florianópolis.

Félix, G.; Marenzi, R. C.; Polette, M. \& Netto, S. A. 2016. Landscape Visual Quality and Meiofauna Biodiversity on Sandy Beaches. Environmental Management. 12p.

Tuan, Y. 1983. Espaço e lugar: a perspectiva da experiência. São Paulo. Difel. 25p.

Univali. 2016. Relatório Técnico I - Estudo de Delimitação de duas Unidades de Conservação na Orla de Itajaí.

Venson, G. R. 2009. Estudo da capacidade de carga física e social como uma ferramenta de gestão ambiental da praia brava do município de Itajaí no litoral centro-norte de Santa Catarina. 160 f. Dissertação (Mestrado em Tecnologia e Gestão Ambiental. Ecossistemas Aquáticos) Universidade do Vale do Itajaí, Itajaí.
Submetido: Março/18 Revisado: Julho/18 Aceito:Fevereiro/19 Publicado: Maio/19 